\section{Proceedings of the 14th meeting of the Goose Specialist Group of the IUCN Species Survival Commission and Wetlands International}

\section{Bart Ebbinge}

Alterra, Postbus 47, NL-6700AA, Wageningen, Netherlands; e-mail: bart.ebbinge@wur.nl

The 14th meeting of the Goose Specialist Group (GSG) was hosted by the University College in NordTrøndelag (HiNT) at the Faculty of Agriculture and Information Technology in Steinkjer, Norway from 17-21 April 2012. Seventy participants from 18 different countries attended the meeting, and delivered 46 oral presentations and 6 poster presentations. Focus was on the Svalbard populations of Pink-footed (Anser brachyrhynchus) and Barnacle geese (Branta leucopsis), on Greylag Geese (Anser anser) nesting in Norway and wintering in Spain, but the programme also included more general themes, such as how Greater White-fronted Geese follow the green wave during spring migration though central Russia, the breeding biology of the strongly increasing population of Barnacle Geese on Kolguyev Island, Russia, and a circumpolar meta-analysis on the impact of global warming on breeding success of arctic-nesting geese.

The marked increase in numbers in most, but not all (!), goose populations is met with the request to control goose numbers at a desired level in several countries. This, however, requires sound knowledge about the impact of control measures on the population dynamics of geese, and such knowledge is lacking in most European countries. It was therefore encouraging to hear that both Denmark and Norway have made funds available for research into such control measures envisaged for the population of Pink-footed Geese nesting on Svalbard, which is one of the best studied goose populations in the world with both a high proportion of marked individuals and very accurate annual censuses of the entire population.

On behalf of the board of the Goose Specialist Group I would like to acknowledge all sponsors that made this meeting possible. The foundation "Stichting Support Meetings of the Goose Specialist Group" managed to obtain $€ 10,000$ to support 13 participants from 7 countries covering part of their travelling and conference costs. This support was generated from generous gifts from the Dutch Faunafonds, WWF-NL and Wetlands International. The meeting itself was sponsored by the hosts at HiNT, and by the Norwegian Directorate for Nature Management and the Department of the Environment at the County Governors Office (Fylkesmannen i Nord-Trøndelag).

I would like to congratulate the editorial team consisting of Jouke Prop, Carl Mitchell, and Paul Shimmings, with the completion of the present proceedings of this conference in Ornis Norvegica as a tangible result of this meeting.

Bart Ebbinge (Chairman GSG) Also on behalf of Thomas Heinicke, Jesper Madsen, Ingunn Tombre and Berend Voslamber (board members GSG attending the meeting).

Received 25 February 2013. Accepted 05 June 2013. Guest editor: Paul Shimmings 